$\mathrm{P}$ етикулярный Эритематозный муциноз

О.В. Антонова' ${ }^{1}$ П.Н. Трофримов², И.Э. Белоусова ${ }^{1}$, А.В. Самцов ${ }^{1}$

1 ФГБВОУ ВПО «Военно-медицинская академия им. С.М. Кирова» МО РФ 194044, Санкт-Петербург, ул. Академика Лебедева, д. 2

2 ФГБУ «Федеральный медицинский исследовательский центр имени В.А. Алмазова» Минздрава России 197341, Санкт-Петербург, ул. Аккуратова, д. 2

Представлены современные данные, касающиеся клинической картины, патоморфологических особенностей и вариантов лечения ретикулярного эритематозного муциноза. Высказана точка зрения на тождественность таких нозологических форм, как ретикулярный эритематозный муциноз, опухолевидная красная волчанка и лимороцитарная инорильтрация Джесснера — Каносра.

Ключевые слова: ретикулярный эритематозный муциноз, муцин.

Контактная инсформация: Іесја@bk.ru. Вестник дерматологии и венерологии 2014; (5): 96_99.

\title{
Reticular erythematous mucinosis
}

\section{O.V. Antonova1, P.N. Trofimov², I.E. Belousova1, A.V. Samtsov}

${ }^{1}$ Military Medical Academy named after S.M. Kirov Ministry of Defense of the Russian Federation Akademika Lebedeva str., 2, St. Petersburg, 194044, Russia

${ }^{2}$ Federal Almazov Medical Research Centre Akkuratova str., 2, St. Petersburg, 197341, Russia

This article presents modern data related to the clinical picture, pathologic features and treatment options of reticular erythematous mucinosis (REM). There is an opinion that REM, lupus erythematosus tumidus and Jessner — Kanof lymphocytic infiltration of the skin are similar nosological forms.

Key words: reticular erythematous mucinosis, mucin.

Corresponding author: lecja@bk.ru. Vestnik Dermatologii i Venerologii 2014; 5: 96_99. 
Ретикулярный эритематозный муциноз (РЭМ) редкое заболевание, поражающее преимущественно женщин среднего возраста и характеризующееся возникновением эритематозных пятен, узелков и бляшек, располагающихся в сетчатом порядке. В 1974 г. G. Steigleder и соавт. впервые описали РЭМ [1]. Причины развития РЭМ остаются неизвестными, нозологическая принадлежность заболевания до сих пор не определена: одни авторы считают его разновидностью первичного муциноза кожи, другие - формой красной волчанки [2]. Малочисленные научные публикации, посвященные РЭМ, описывают лишь единичные случаи или небольшие группы больных [2, 3].

В связи с редкостью данного заболевания и отсутствием в отечественной литературе работ, описывающих РЭМ, приводим наши наблюдения.

Пациентка В., 39 лет, обратилась в клинику кожных и венерических болезней Военно-медицинской академии им. С.М. Кирова в декабре 2012 г. с жалобами на высыпания в области груди, не сопровождающиеся субъективными ощущениями. Больна в течение 2 лет. Периодически отмечала самопроизвольное разрешение высыпаний. Самостоятельно применяла крем «Дермовейт» с непродолжительным положительным эффректом.

При осмотре поражение кожи носит ограниченный характер с локализацией в области груди, где на фоне видимо неизмененной кожи видны отечные пятна и папулы красного цвета (рис. 1).

Больной была выполнена диагностическая биопсия. При гистологическом исследовании под умеренно атрофированным эпидермисом в верхней половине дермы обнаруживались расширенные сосуды, окруженные плотными «муфртообразными» лимфоцитарными инсрильтратами. Между коллагеновыми волокнами в сосочковой части дермы и верхних отделах сетчатой части дермы располагались отложения муцина.

На основании данных анамнеза, клинической картины и гистологического исследования был установлен окончательный диагноз: РЭМ.

Больной была назначена наружная терапия топическими ингибиторами кальциневрина - крем «Элидел» $1 \%$. Достигнута полная ремиссия.

Пациентка Б., 37 лет, обратилась в клинику кожных и венерических болезней Военно-медицинской академии им. С.М. Кирова в феврале 2013 г. с жалобами на распространенные высыпания, не сопровождающиеся субъективными ощущениями. Больна в течение 8 лет. Самостоятельно не лечилась. Неоднократно обращалась к дерматологам по месту жительства - диагноз установлен не был.

При осмотре на коже груди, живота и верхней части спины видны участки сетчатой эритемы, уртикароподобные бляшки и папулы красного цвета (рис. 2a, б).

Пациентке была выполнена диагностическая биопсия. При гистологическом исследовании в верхней и

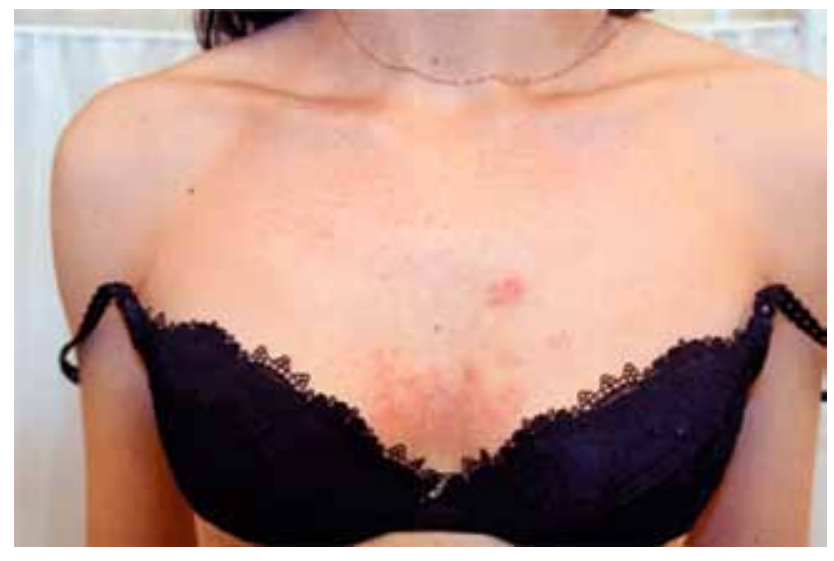

Рис. 1. РЭМ. Отечные пятна и папулы красного цвета
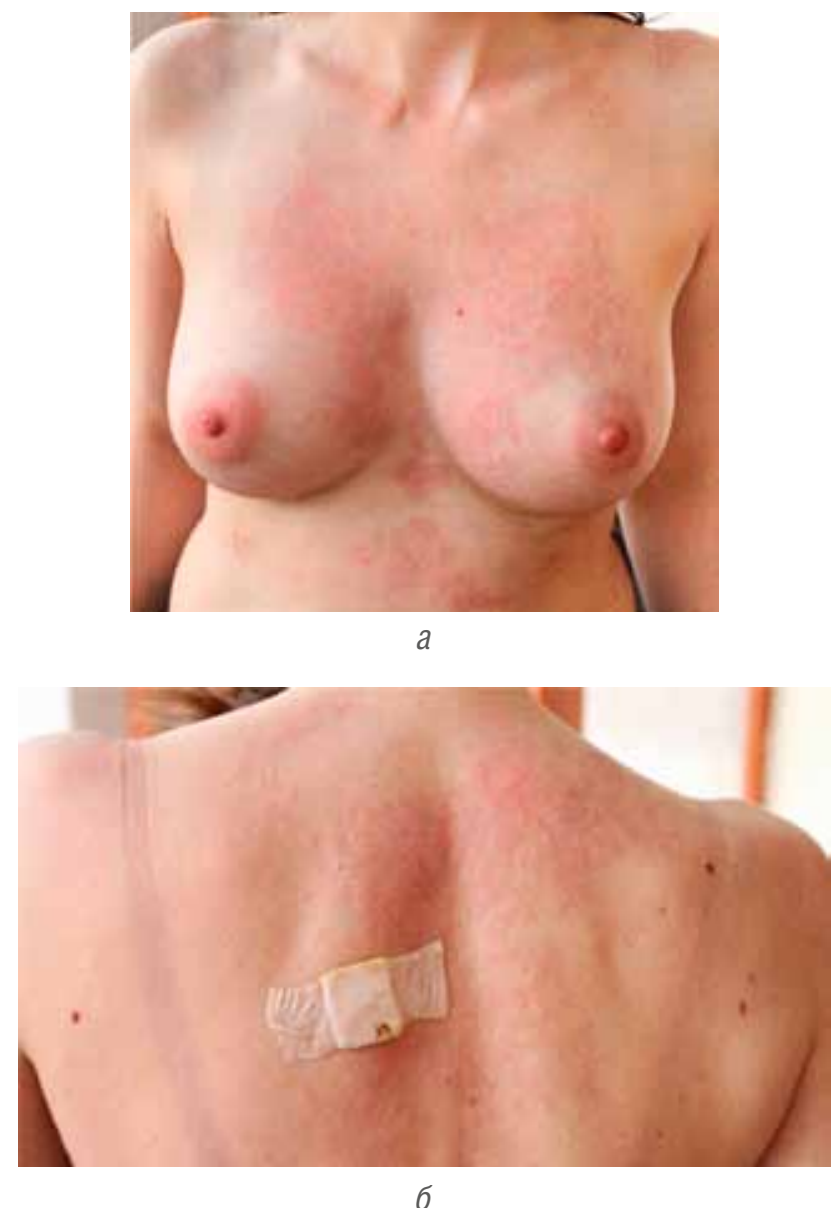

РЭМ. Участки сетчатой эритемы, урти-

Рис. 2. кароподобные бляшки и папулы красного цвета на коже груди (a) и верхней части спины (б) 

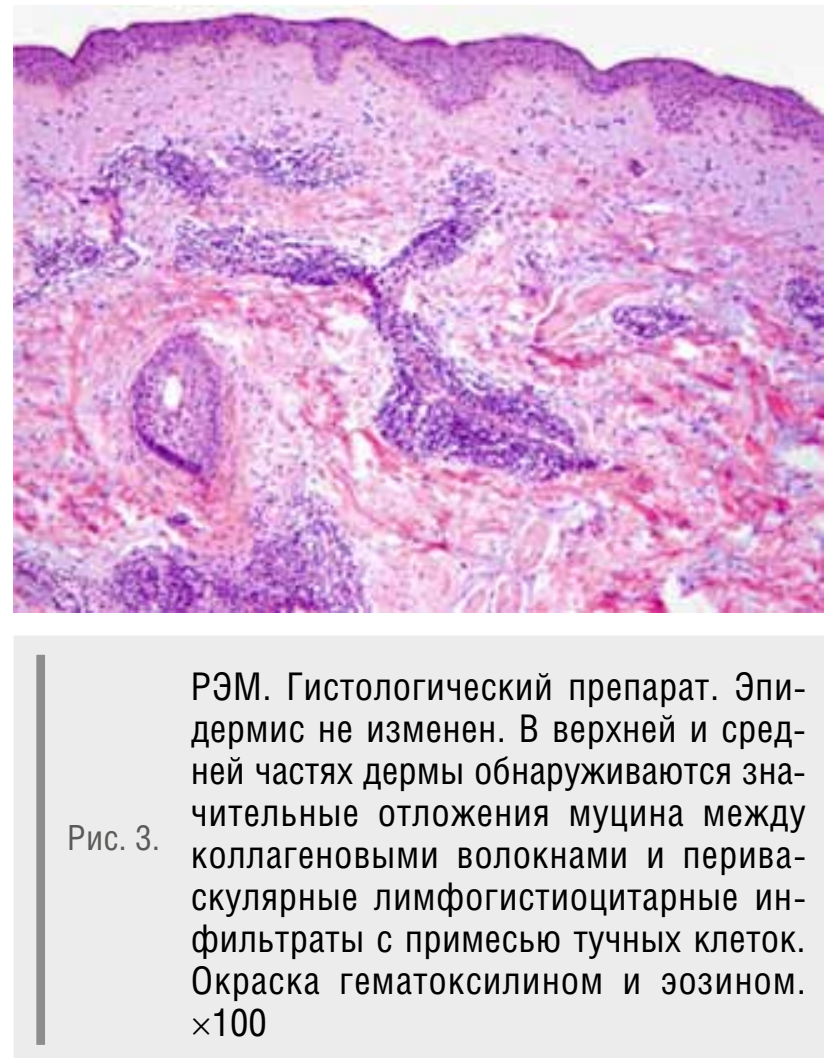

средней частях дермы обнаруживались значительные отложения муцина между коллагеновыми волокнами и периваскулярные лимфогистиоцитарные инфильтраты с примесью тучных клеток. Эпидермис не изменен (рис. 3).

На основании данных клинической картины и гистологического исследования был установлен окончательный диагноз: РЭМ.

По поводу РЭМ больная получала лечение: гидроксихлорохина сульсрат 200 мг; наружная терапия с применением топических ингибиторов кальциневрина (крем «Элидел» 1\%). На фооне терапии достигнута полная ремиссия.

\section{Обсуждение}

В настоящее время не существует единого понимания этиологии и патогенеза ретикулярного эритематозного муциноза. РЭМ чаще встречается у женщин среднего возраста [2]. Клиническая картина заболевания представлена пятнами, папулами и бляшками красного цвета с незначительной инфильтрацией, располагающимися на коже в виде колец, полициклических или сетчатых фигур. Высыпания локализуются в центральной части спины, груди и верхних отделах живота, могут сопровождаться зудом [2, 3]. Роль инсоляции в развитии заболевания не определена, описаны случаи как улучшения, так и обострения течения заболевания под воздействием УФ-облучения [2]. Найдены ассоциации РЭМ с эндокринными нарушениями, в частности с дисфункцией щитовидной железы, злокачественными новообразованиями [3].

Гистологическая картина РЭМ характеризуется изменениями в дерме: вокруг кровеносных сосудов в верхней и средней частях дермы образуются умеренной плотности лимфроцитарные инфильтраты с единичными мастоцитами и гистиоцитами. Часто инфильтраты располагаются вокруг эккринных желез и перифолликулярно. Характерным патоморфологическим признаком РЭМ является отложение муцина в верхней и средней частях дермы. Депозиты муцина более заметны вокруг придатков кожи и клеточных инфильтратов. Может обнаруживаться фррагментация эластических волокон. Эпидермис обычно неизменен, возможен незначительный спонгиоз [4].

При исследовании кожи методом прямой реакции иммунофлюоресценции (РИФ) у $27 \%$ больных ретикулярным эритематозным муцинозом выявляется отложение иммуноглобулинов M(lgM) вдоль базальной мембраны. Однако необходимо учитывать, что при исследовании кожи здоровых людей, подвергшейся инсоляции, доля положительных результатов РИФ имеет схожие величины [2]. Положительные серологические реакции (ANA) встречаются редко [2, 4].

Проанализировав литературу и учитывая полученный опыт авторов, можно сказать, что первая линия терапии включает в себя пероральный прием гидроксихлорохина, хлорохина. Альтернативными методами лечения можно считать наружную терапию топическими стероидами, топическими ингибиторами кальциневрина. Также описано успешное применение UVA1-фрототерапии [6].

В обоих представленных случаях отмечалась характерная для РЭМ клиническая картина, данные гистологического исследования позволили окончательно верифицировать диагноз. У обеих больных на фоне терапии была достигнута ремиссия заболевания.

Существует ряд состояний, гистологическая и клиническая картина при которых весьма похожа на таковую при РЭМ. К ним относят лимфоцитарную инфильтрацию Джесснера - Канофа и опухолевидную красную волчанку (KB). На сегодняшний день нет убедительных данных о единстве или различии этих дерматозов и общепринятого мнения об их нозологической принадлежности. Трудности в дифференциальной диагностике опухолевидной КВ, лимфоцитарной инфильтрации Джесснера - Канофа и РЭМ заключаются в отсутствии специфических диагностических критериев, характерных для каждого из этих заболеваний. Диагноз устанавливается только на основании клинических и патоморфологических данных. Схожая клиническая картина (уртикароподобные бляшки и папулы, которые часто располагаются на открытых участках кожи), отсутствие серологических из- 
менений, гистологическая картина (периваскулярные и перифолликулярные лимфоцитарные инфильтраты с отложением муцина в дерме), эффрективное применение гидроксихлорохина, хлорохина подтверждает фракт общности этих заболеваний [2]. Ряд авторов относят РЭМ к первичной форме кожных муцинозов. Мы разделяем точку зрения других авторов, которые придерживаются мнения, что РЭМ, лимфоцитарная инфильтрация Джесснера - Канофа и опухолевидная КВ представляют собой одно и то же состояние [5]. І І

\section{Литература}

1. Steigleder G.K., Gartmann H., Linker U. REM syndrome: reticular erythematous mucinosis (round-cell erythematosis), an ewentity? $\mathrm{Br} \mathrm{J}$ Dermatol 1974; 91 (2): 191-199.

2. Rongioletti F., Merlo V., Riva S. et al. Reticular erythematous mucinosis: are view of patients characteristics, associated conditions, therapy and outcome in 25 cases. British Journal of Dermatology 2013; 169 (6): 1207-1211.
3. Kreuter A., Scola N., Tigges C. et al. Clinical features and efficacy of antimalarial treatment for reticular erythematous mucinosis: a case series of 11 patients. Arch Dermatol 2011; (147): 710-715.

4. Braddock S.W., Kay H.D., Maennle D. et al. Clinical and immunologic studies in reticular erythematous mucinosis and Jessner's lymphocytic infiltrate of skin. Journal of the American Academy of Dermatology 1993; 28 : 691-695.
5. Kozlovskaya V.V., Tikhonovskaya I.V., Kozlovsky V.I. Peculiarities of clinical picture and differential diagnostics of tumor-like lupus erythematosus. Klin med 2013; 4: 65—69. [Козловская В.В., Тихоновская И.В., Козловский В.И. Особенности клиники и диффреренциального диагноза опухолевидной волчанки. Клин мед 2013; (4): 65-69.]

6. Amherd-Hoekstra A., Kerl K., French L.E. et al. Reticular Erythematous Mucinosis in an atypical pattern distribution responds to UVA1 phototherapy 2014; 28 (5): 672—673.

об авторах:

О.В. Антонова - клинический ординатор кафедры кожных и венерических болезней ФГБВОУ ВПО «Военно-медицинская академия им. С.М. Кирова» МО РФ, Санкт-Петербург

П.Н. Трофимов - младший научный сотрудник научно-исследовательской лаборатории ревматологии ФГБУ «Федеральный медицинский исследовательский центр им. В.А. Алмазова», Санкт-Петербург

И.Э. Белоусова — доцент кафедры кожных и венерических болезней ФГБВоУ ВПО «Военно-медицинская академия им. С.М. Кирова» МО РФ, Санкт-Петербург

А.В. Самцов - зав. кафредрой кожных и венерических болезней ФГБВОУ ВПо «Военно-медицинская академия им. С.М. Кирова» МО РФ, Санкт-Петербург

\section{Конфликт интересов}

Авторы заявляют об отсутствии потенциального конфликта интересов, требующего раскрытия в данной статье 